Baseline

\title{
Characterization of polychlorinated biphenyl congeners in surface sediments of the Changjiang Estuary and adjacent shelf by high-resolution sampling and high-resolution mass spectrometry
}

\author{
Aifeng Liu ${ }^{\mathrm{a}}$, Yawei Wang ${ }^{\mathrm{b}}$, Mo Xian ${ }^{\mathrm{a}}$, Zongshan Zhao ${ }^{\mathrm{a}, *}$, Bin Zhao ${ }^{\mathrm{c}}$, Jinpeng Wang ${ }^{\mathrm{c}}$, Peng $\mathrm{Yao}^{\mathrm{c}, *}$ \\ ${ }^{\text {a } C A S ~ K e y ~ L a b o r a t o r y ~ o f ~ B i o b a s e d ~ M a t e r i a l s, ~ Q i n g d a o ~ I n s t i t u t e ~ o f ~ B i o e n e r g y ~ a n d ~ B i o p r o c e s s ~ T e c h n o l o g y, ~ C h i n e s e ~ A c a d e m y ~ o f ~ S c i e n c e s, ~ Q i n g d a o ~ 266101, ~ C h i n a ~}$ \\ b State Key Laboratory of Environmental Chemistry and Ecotoxicology, Research Center for Eco-Environmental Sciences, Chinese Academy of Sciences, P.O. Box 2871, \\ Beijing 100085, China \\ ${ }^{c}$ Key Laboratory of Marine Chemistry Theory and Technology, Ministry of Education, Ocean University of China, Qingdao 266100, China
}

\section{A R T I C L E I N F O}

\section{Keywords:}

Polychlorinated biphenyl

Sediment

Changjiang Estuary

Distribution

High-resolution

\begin{abstract}
A B S T R A C T
Due to limited samples and low-resolution analysis, conflicting findings on major polychlorinated biphenyl (PCB) congeners and their origins remain in the East China Sea (ECS). Based on high-resolution sampling and high-resolution mass spectrometry analysis, 72 surface sediment samples from the Changjiang Estuary and adjacent ECS shelf were determined to characterize 39 PCB congeners. PCBs $\left(\sum_{39} \mathrm{PCBs}\right)$ ranged from 0.003 to $16.18 \mathrm{ng} / \mathrm{g} \mathrm{dw}$, presenting a decreasing seaward trend. Tri-, tetra- and penta-CBs were the main components, accounting for $>64 \%$ of $\Sigma_{39} \mathrm{PCBs}$ in most samples. Tetra-CBs were the dominant congeners, corresponding to results of sediments from Changjiang middle reach and soils from Changjiang Delta. Comparison between PCBs and sediment properties indicated there may be a deposition boundary of $30^{\circ} \mathrm{N}$. In the north, the spatial distribution of PCBs is controlled by Changjiang input and hydrodynamic conditions, while in the south closely related to combination of local source and riverine input.
\end{abstract}

Polychlorinated biphenyls (PCBs), one of priority persistent organic pollutants (POPs) in the Stockholm Convention (Stockholm Convention 2015), can often be released into the environment during the processes of production, transportation and usage (Bigus et al. 2014). Although PCBs have been banned legally in China since 1974 (Yang et al. 2011), large amount of e-waste recycling still acts as an important alternative origin of environmental PCBs (Yang et al. 2012). During their life cycles, PCBs have transferred all over the world (Jonsson et al. 2003) and some PCB congeners have been documented to be closely related to severe toxicological effects (Li et al. 2016).

Usually, sediments are considered to be the final sink of PCBs after their transfer, exchange and deposition between soil, water, gas and sediment (Jonsson et al. 2003). The East China Sea (ECS), one of the largest shelf seas in the world, is an important sink of terrigenous matters from Changjiang basin. Every year, Changjiang discharges about $0.5 \mathrm{Gt}$ terrestrial particulate matter to the ECS with 2-5 Mt. being of organic matter which could adsorb POPs (Wang et al. 2008). Large amounts of PCBs emitted from industrial development, sewage discharge and transportation in the Changjiang basin would be transferred into the ECS and buried in the sediments (Liu et al. 2010).

As an important sink of PCBs from Changjiang basin, quite a few efforts on PCBs in the ECS and its adjacent areas (Table 1) have been performed in recent years (Ono et al. 2012; Yang et al. 2011; Yang et al. 2012; Zhou et al. 2012). Through these productive studies, the pollution levels, spatial distributions, PCBs congeners and origins of these sedimentary PCBs have been clearly revealed. For example, PCBs with low chlorinated PCBs being of the predominated congeners are one of the most common POPs in the ECS and they are proposed to be from PCB products, surface soil, etc. (Wang et al. 2016; Yang et al. 2011). However, the conflicted results on major PCB congeners (tri-CBs, tetraCBs or penta-CBs) (Lai et al. 2015; Wang et al. 2016; Yang et al. 2011) and ambiguous source analysis on PCBs origins (river input, wastewater discharge or e-waste recycling) (Duan et al. 2013; Fan et al. 2014; Yang et al. 2012) have also been reported because of the limited sampling sites and defective analyzing PCB congeners. By comparison with lipid biomarkers produced from terrestrial plants and marine phytoplankton, Fan. et al. have noted that there is a rough boundary $\left(29^{\circ} \mathrm{N}\right.$ in the inner shelf) for sedimentary PCBs from Changjiang transport and local coastal discharge (Fan et al. 2014).

In this study, sedimentary PCBs in the inner shelf adjacent to Changjiang Delta have been more critically studied via high-resolution sampling and high-resolution mass spectrometry analysis. The purpose

\footnotetext{
* Corresponding authors.

E-mail addresses: zhaozs@qibebt.ac.cn (Z. Zhao), yaopeng@ouc.edu.cn (P. Yao).
} 
is to identify PCBs congeners more distinctly and to further distinguish the location of the boundary describing the characteristics of PCBs distributions.

Surface currents in the ECS shelf consist of the Changjiang diluted freshwater carrying terrestrial organic matter into the ECS, the northward flow of the warm and saline Taiwan Warm Current (TWC), and relatively cold and brackish southward-flowing Jiangsu and Zhejiang-Fujian Coastal Current (ZFCC). The vast majority of the sediments discharged from the Changjiang is ultimately deposited in the Changjiang Estuary and southern inner shelf of the ECS (Milliman et al. 1985). Seventy-two surface sediment samples (depth: $0-3 \mathrm{~cm}$ ) were collected from the adjacent coastal regions of Changjiang Estuary during a cruise in March 2014 using a stainless steel box-corer $(40 \mathrm{~cm} \times 60 \mathrm{~cm} \times 50 \mathrm{~cm})$ from the R/V Runjiang 1 . The detailed sampling sites were shown in Fig. 1 and Table S1. All samples were then freeze-dried, homogenized, and stored at $-20{ }^{\circ} \mathrm{C}$ until analysis.

The sediment sample $(5.0 \mathrm{~g})$ was spiked with ${ }^{13} \mathrm{C}$-labeled mono- to deca-CBs (РCB 3, 15, 28, 52, 118, 153, 180, 194, 208, and 209, Cambridge Isotope Laboratories, Inc., Andover, MA, USA), and extracted using an accelerated solvent extraction system (ASE300, Dionex, USA) with dichloromethane $/ n$-hexane $(1: 1, v / v)$. The extract was concentrated with a rotary evaporator after the addition of activated copper powder to remove sulfur and then cleaned using a combination silica column filled with $1 \mathrm{~g}$ silica, $4 \mathrm{~g}$ basic silica $(1.2 \%, w / \mathrm{w})$, $1 \mathrm{~g}$ silica, $8 \mathrm{~g}$ acidic silica $(30 \%, w / \mathrm{w}), 2 \mathrm{~g}$ silica, and $4 \mathrm{~g}$ anhydrous sodium sulfate from bottom to top. The column was prewashed with $80 \mathrm{~mL} n$-hexane. After sample loaded, PCBs were eluted with $100 \mathrm{~mL} n$ hexane which was finally concentrated to $100 \mu \mathrm{L}$. The internal standard, ${ }^{13}$ C-labeled PCB standards (PCB 77 and PCB 101) were added before the instrumental analysis.

Thirty-nine congeners, PCB $1,3,8,10,15,18,19,28,33,37,44$, 52 , 74, 77, 81, 87, 95, 99, 101, 105, 110, 114, 118, 138, 149, 151, 153, 155, 170, 180, 188, 189, 191, 194, 199, 205, 206, 208, 209, numbered according to the IUPAC nomenclature, were analyzed using an Agilent 7200 GC-Q-TOF-MS (Agilent Technologies, Santa Clara, USA) equipped with an electron impact (EI) ion source. A quartz capillary column (DB5MSUI $30 \mathrm{~m} \times 0.25 \mathrm{~mm}$ i.d., $0.25 \mu \mathrm{m}$ film thickness) was used for the chromatographic separation. The GC oven temperature program began with $1 \mathrm{~min}$ hold at $60^{\circ} \mathrm{C}$ followed by heating to $120^{\circ} \mathrm{C}$ at $40{ }^{\circ} \mathrm{C} / \mathrm{min}$ and then to $310{ }^{\circ} \mathrm{C}$ at $5{ }^{\circ} \mathrm{C} / \mathrm{min}$. The sample $(1 \mu \mathrm{L})$ was injected under splitless mode, and the injector temperature was set at $280^{\circ} \mathrm{C}$. Ultrapure helium was used as the carrier gas at a flow rate of $1.0 \mathrm{~mL} /$ min. The auxiliary heating and EI source temperatures were set at $280^{\circ} \mathrm{C}$ and $250{ }^{\circ} \mathrm{C}$. A solvent delay of 5 min was used to prevent damage in the ion source filament.

Grain-size composition of the surface sediments was measured using a laser Particle Size Analyzer (Mastersizer 2000, Malven Instruments Ltd., UK) (Yao et al. 2014). Particle sizes $<4 \mu \mathrm{m}$ were considered clays, 4 to $63 \mu \mathrm{m}$, silts, and sands were larger than $63 \mu \mathrm{m}$. Total organic carbon (TOC) and total nitrogen (TN) were analyzed using a Vario MICRO cube elemental analyzer (EA) (Elementar, Germany) (Wang et al. 2015). The detailed sediment information, including particle sizes, TOC\%, TN\% and water depth were shown in Table S1 (Supplementary Data).

All solvents used were of pesticide grade. In order to avoid the crosscontamination, a laboratory blank (anhydrous sodium sulfate) and a surrogate spiking blank sample were treated with each batch (10 samples) of samples. Relative standard deviation of the recoveries for the spiking blank samples ranged from $3 \%$ to $10 \%$. The method detection limits ranged from 0.0002 to $0.002 \mathrm{ng} / \mathrm{g} \mathrm{dw}$. The average recoveries of the surrogate PCBs ranged from $60 \%$ to $110 \%$. All the results were corrected with the internal standards.

SURFER 8.0 was used to plot the sampling map and contour maps. A contour map is a two-dimensional representation of three-dimensional data. The first two dimensions are the $\mathrm{X}$ and $\mathrm{Y}$ coordinates of the sampled stations. The third dimension (Z, total concentrations of PCBs) 


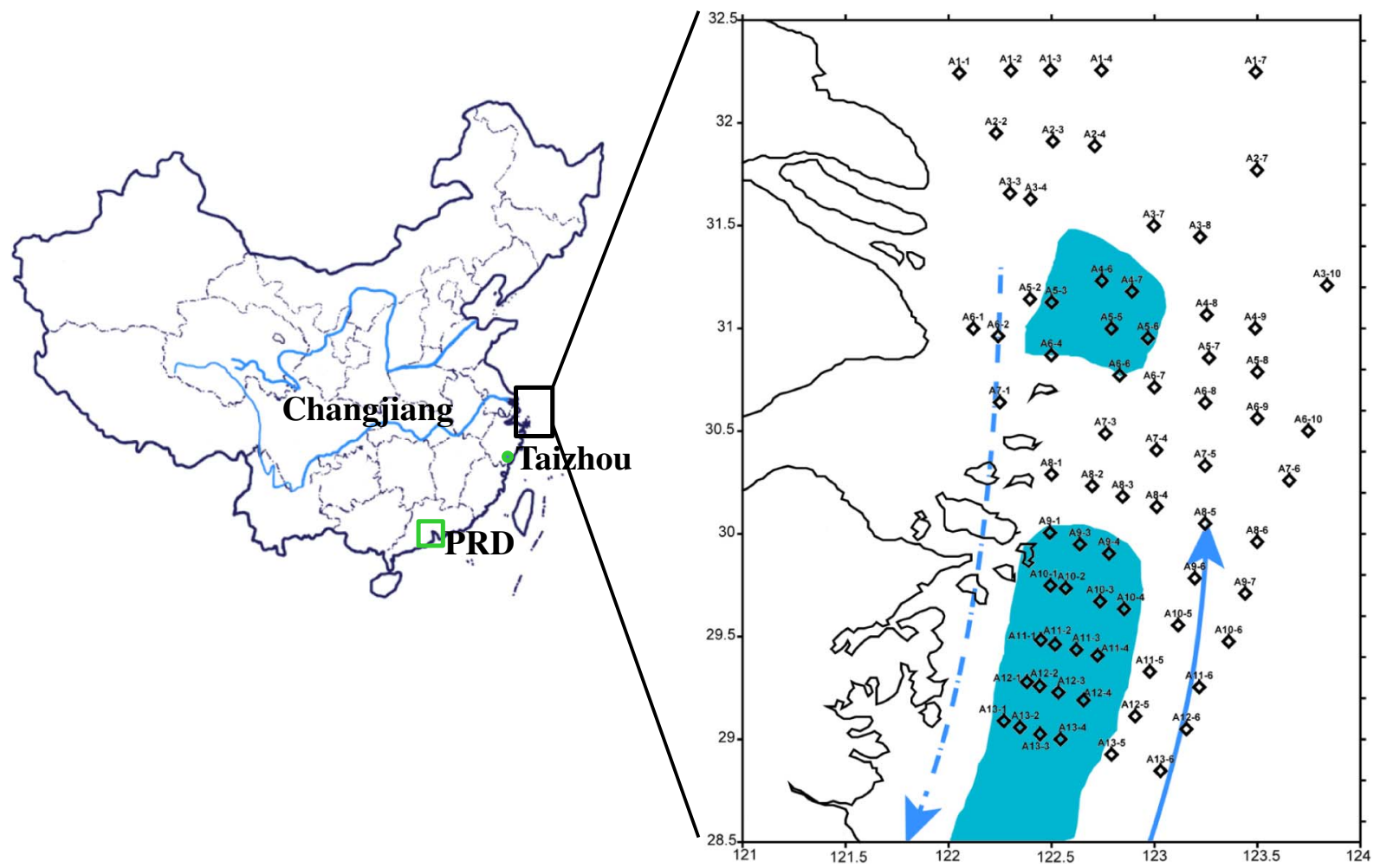

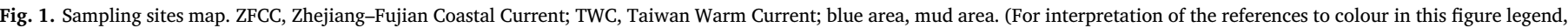
the reader is referred to the web version of this article.)

is represented by different colors filled in intervals of lines of equal value (lines not show). The Spearman's correlation analysis was done through the software package SPSS Statistics 20.0 (SPSS Inc., Chicago, USA). The ratios for PCB congeners in total PCBs were calculated and ploted by OriginPro 9.0.0 (OriginLab Corporation, USA).

For all the 72 surface sediment samples, 39 PCB congeners with 1-10 Cl atoms were analyzed and the total contents of 39 PCB congeners ( $\Sigma_{39} \mathrm{PCBs}$ ) ranged from 0.003 to $16.18 \mathrm{ng} / \mathrm{g} \mathrm{dw}$, with the mean value of $3.41 \mathrm{ng} / \mathrm{g} \mathrm{dw}$. The $\Sigma_{39} \mathrm{PCBs}$ level was comparable to some other reports from the ECS (5.08-19.64 ng/g dw) (Yang et al. 2012), including Zhoushan Archipelago and Xiangshan Harbor (1.48-7.94 ng/ $\mathrm{g} \mathrm{dw}$ ) (Wang et al. 2016). Compared with the sediments collected from the Wuhan reach (1.2-45.1 ng/g dw) and the soils collected from Changjiang Delta (0.46-116.4 ng/g dw) (Zhang et al. 2011), PCBs contents in the Changjiang Estuary and the inner shelf of the ECS were at lower levels (Yang et al. 2009).

The spatial distribution patterns of $\Sigma_{39} \mathrm{PCBs}$ in our study were in accordance with other well known POPs, such as PAHs (Lui and Zhai 2005), SCCPs (Zhao et al. 2013), and OCPs (Yang et al. 2005) in the ECS. POPs are tended to be adsorbed on the fine particles and deposited with them. Sediments from Changjiang are transported to ECS mainly through across-shelf diffusion and a strong along-shelf advection, so that large amounts of Changjiang-derived sediments depositing along the shelf (Liu et al. 2006). Therefore, PCBs mainly accumulated at the coastal areas near the Changjiang Estuary and totally presented a seaward decreasing trend (Fig. 2) (Fan et al. 2014). Take transect of A6 along the direction of Changjiang diluted freshwater for example, PCBs contents decrease remarkably with distance from Changjiang Estuary to the outer shelf (Fig. 3), except for site of A6-1 with few fine particles adsorbing organic matters deposited because of stronger hydrodynamics (Gao et al. 2013). In all, the highest values were located at the Changjiang Estuary (A6-2) and Zhoushan Archipelago (A9-1), corresponding to the direct land-derived discharge and the "marginal filter" effect (Yang et al. 2012). Similar to previous reports on sedimentary PCBs in Changjiang Estuary, the relative lower values at site A3-3 and
A3-4 than other Changjiang Estuary sites could be attributed to the seawater intrusion (Fan et al. 2014; Gao et al. 2013).

The total contents of seven PCB indicators $\left(\Sigma_{7 \mathrm{I}} \mathrm{PCBs}\right.$, PCB 28, 52, $101,118,138,153 / 132$ and 180$)$ are often recommended as the ecotoxicological assessment criteria (EAC, $1.0-10.0 \mathrm{ng} / \mathrm{g}$ ) (OSPAR Commission 2000) to indicate their hazards to ecological system and human health. In this study, for $\Sigma_{7 \mathrm{I}} \mathrm{PCBs}$ (n.d. $-2.78 \mathrm{ng} / \mathrm{g}$ ), 19 of 72 sediment samples exceed the low end value of EAC $(1.0 \mathrm{ng} / \mathrm{g})$, and were much lower than the high end value of $10.0 \mathrm{ng} / \mathrm{g}$, indicating the extremely low ecological risks of PCBs in the ECS. Even so, their ecological risks to high trophic level organisms from the anthropic activities and re-suspension cannot be neglected due to their bioaccumulation and biomagnification via food web (Malisch and Kotz 2014).

The detection frequencies for all PCB congeners ranged from $1.3 \%$ to $94.6 \%$, with higher values $(18.9 \%-94.6 \%)$ for low chlorinated PCBs (mono- to penta-CBs) than high chlorinated PCBs (hexa- to deca-CBs, $1.3 \%-56.8 \%$ ) (Table S2, Supplementary Data). The high detection frequencies of low chlorinated PCBs are consistent to previous reports of PCBs in the surface sediments of the ECS (Yang et al. 2012; Zhou et al. 2012), and typical drinking water in Jiangsu Province which are closely related to Changjiang (Hong et al. 2009). The results can be attributed to the higher utilization frequency and higher proportion of low chlorinated PCBs in China (Jiang et al. 2007). High-chlorinated PCBs were mainly accumulated at the Changjiang Estuary (site A5-2, A5-3, A5-5, A6-2, A6-4) and the inner shelf close to Zhoushan Island (A7-3, A8-2, A8-3, A9-1) (Fig. 2) because of their higher $K_{o w}$ values which can result in their good adsorption onto the suspended particles and then deposition (Hong et al. 2003). Additionally, the lower water solubility and weaker migration ability of high chlorinated PCBs can also lead to their lower contents as well as lower detection frequencies in the offshore area, thus result in their presentation with high contents at the Changjiang Estuary and the inner shelf.

According to chlorine number of PCB congeners in the ECS, no consensus about primary $\mathrm{PCB}$ congeners have been reported. Most reports presented that tri-CBs are the major congeners, explained by the 

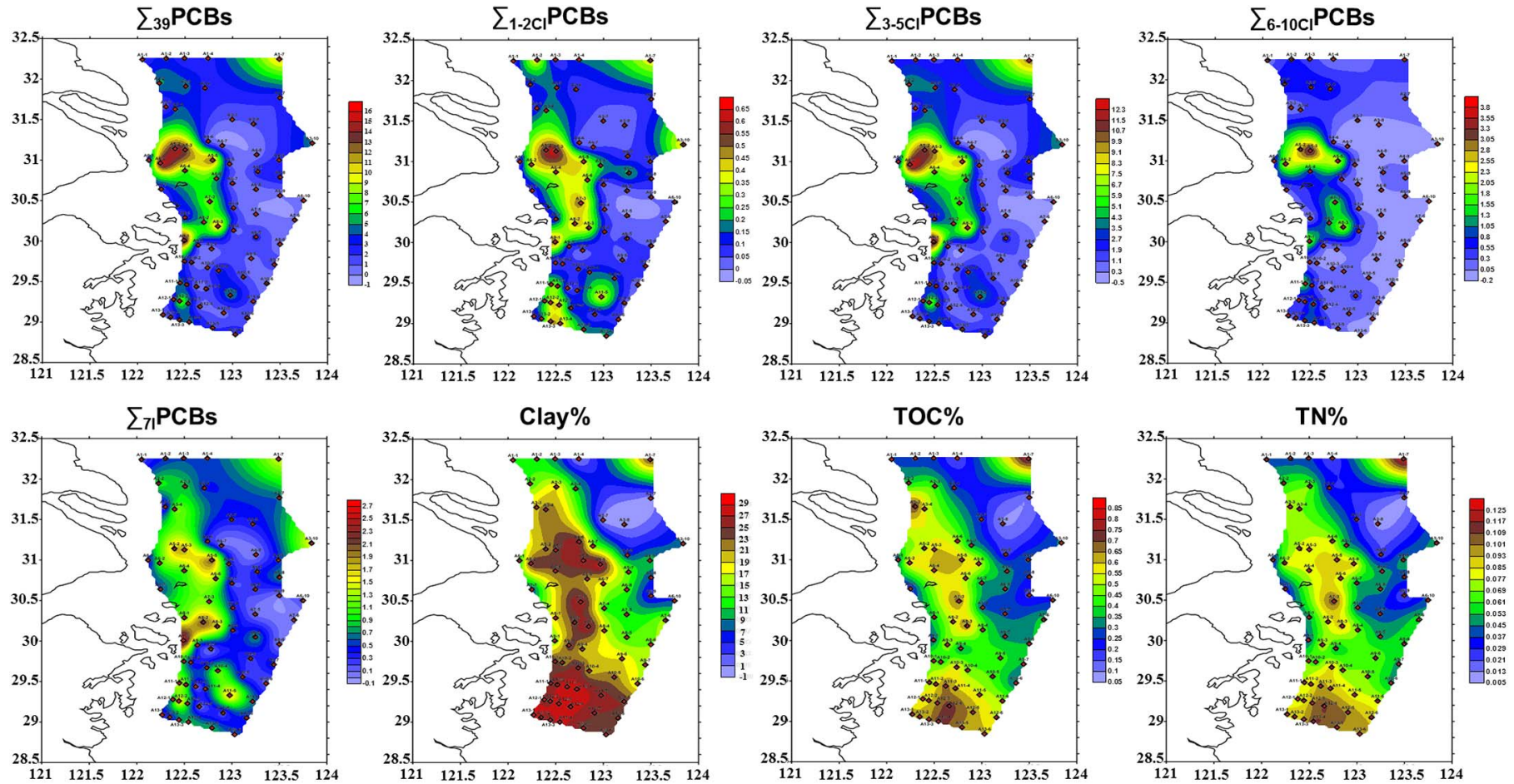

Fig. 2. Spatial distributions of PCBs and the sediment properties of ECS sediment samples.

PCBs production in China from 1960s to 1970s which were also dominated by the tri-CBs, as well as the global PCB products (Adeleye et al. 2016; Duan et al. 2013; Yang et al. 2011). Although penta-CBs was not the dominated PCB products, they were identified as the main composition in the ECS sediment from developed fishery and shipping industries (Wang et al. 2016). In this study, tetra-CBs (Fig. 4) accounted for the highest proportion in all the sediment samples. It has been reported that tetra-CBs were the predominant composition in the surface sediments of Wuhan reach and other middle reach of the Changjiang which might be from surface runoff, industrial wastewater and domestic sewage (Gao et al. 2015; Yang et al. 2009). Meanwhile, the soil from Changjiang Delta (241 top soil samples) were also dominated by tetra-CBs (Sun et al. 2016). Based on the predominance of Changjiang on the matters from river into the ECS and the characteristics of PCBs obtained from the high-resolution sampling and high-resolution mass analysis in this study, it can be concluded that tetra-CBs, not tri-CBs, are very likely to be the major PCB congeners in the ECS.

The contents of individual $\Sigma_{1 \mathrm{Cl}} \mathrm{PCBs}, \Sigma_{2 \mathrm{Cl}} \mathrm{PCBs}, \Sigma_{3 \mathrm{Cl}} \mathrm{PCBs}, \Sigma_{4 \mathrm{Cl}} \mathrm{PCBs}$, $\Sigma_{5 C l}$ PCBs, $\Sigma_{6 \mathrm{Cl}} \mathrm{PCBs}, \Sigma_{7 \mathrm{Cl}} \mathrm{PCBs}, \Sigma_{10 \mathrm{Cl}} \mathrm{PCBs}$ were significant correlated $(p<0.01)$ with that of $\Sigma_{39} \mathrm{PCBs}$, and these factors were also correlated $(p<0.01)$ with each other except $\Sigma_{3 \mathrm{Cl}} \mathrm{PCBs}$ (Table S3, Supplementary Data). High chlorinated PCBs congeners, of which half-lives are often
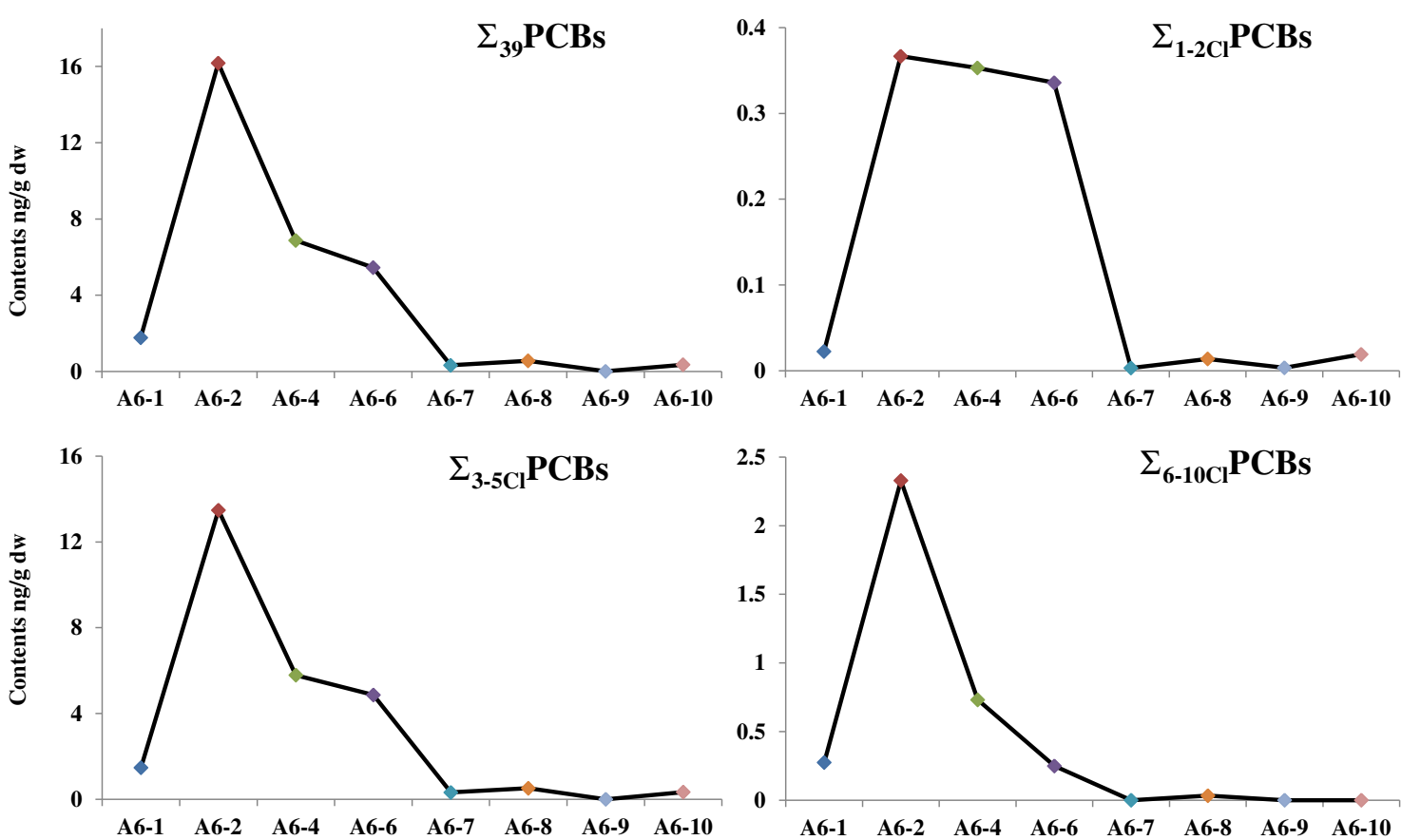

Fig. 3. Transect contents distribution of PCB congeners. 


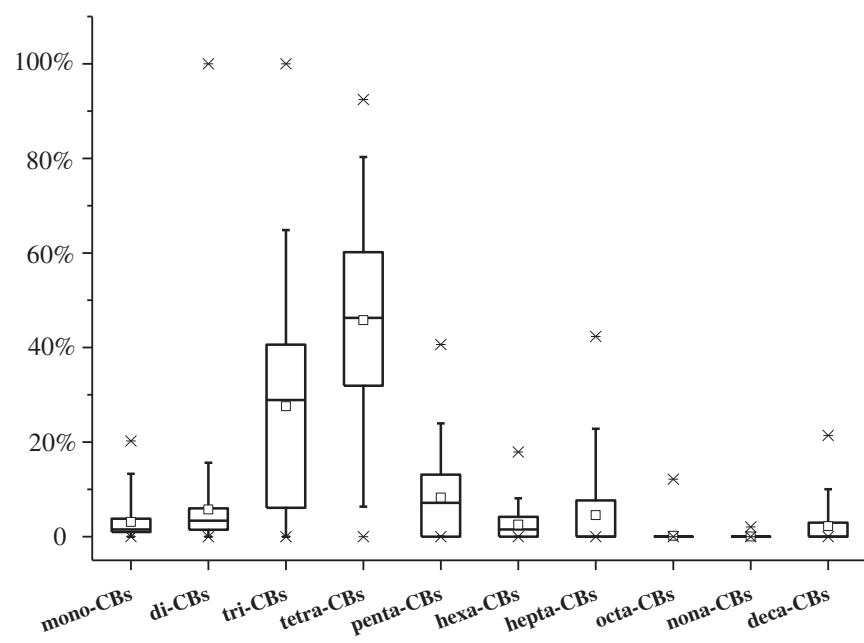

Fig. 4. PCBs congeners composition ratios in the sediment.

longer than 3 years (Sinkkonen and Paasivirta 2000), are prone to degrade to low chlorinated PCB congeners under anoxic conditions in marine sediments (Matturro et al. 2016). This indicated most of low chlorinated PCB congeners are likely from the similar origins and subsequent degradation from high chlorinated PCB congeners. The significant correlation between $\Sigma_{3 \mathrm{Cl}} \mathrm{PCBs}$ and $\Sigma_{2 \mathrm{Cl}} \mathrm{PCBs}$ as well as $\Sigma_{1 C l}$ PCBs $(p<0.01)$ may be attributed to the dechlorination of tri-CBs to di-CBs and mono-CBs in the sediment (Chang et al. 2001). It has been reported that large amounts of tri-CBs has been produced and utilized from 1960s to 1970s and quite a proportion have been transferred into the ECS (Zhang et al. 2004). Therefore, it is reasonable for the close relationship between these three low chlorinated PCB congeners.

As a mixture of many congeners, the environmental behaviors of commercial PCB products are often different. Based on the $\mathrm{Cl}$ content, the application patterns, pollution sources and distribution properties, the PCB congeners were classified as $\Sigma_{39} \mathrm{PCBs}, \Sigma_{1-2 \mathrm{Cl}} \mathrm{PCBs}, \Sigma_{3-5 \mathrm{Cl}} \mathrm{PCBs}$ and $\Sigma_{6-10 \mathrm{Cl}} \mathrm{PCBs}$ to study their deposition characteristics (Fig. 2). Additionally, sediment properties of organic carbon percentage (TOC\%), total nitrogen percentage (TN\%) and clay percentage (clay\%) have also been introduced to investigate the spatial distribution of PCBs.

PCB congener groups, $\Sigma_{39} \mathrm{PCBs}, \Sigma_{1-2 \mathrm{Cl}} \mathrm{PCBs}, \Sigma_{3-5 \mathrm{Cl}} \mathrm{PCBs}$ and $\Sigma_{6-10 C l}$ PCBs, all presented a seaward decreasing trends with highest values located at the Changjiang Estuary and the inner shelf close to Zhoushan Archipelago (Fig. 2). The spatial pattern is largely similar to organic matter index, agreeing well with previous reports on PCBs and other anthropogenic contaminants (Fan et al. 2014). The clay\%, TOC\% and TN\% also presented seaward decreasing trends largely similar to PCBs. $\Sigma_{3-5 \mathrm{Cl}} \mathrm{PCBs}$ were the representative congeners, accounting for $>$ $64 \%$ of $\Sigma_{39} \mathrm{PCBs}$ in 67 of total 72 samples. However, correlation analysis showed that there were relative low correlations $(p>0.01)$ between the classified PCB groups (including $\Sigma_{39} \mathrm{PCBs}$ and $\Sigma_{3-5 \mathrm{Cl}} \mathrm{PCBs}$ ) and clay $\%$, TOC $\%$ and TN\%. Generally, the fine particles are prone to adsorb organic matters being of the dominant factor controlling the sorption of hydrophobic organic pollutants (Dunnivant et al. 2005). Thus, the low correlations between these sediment properties and PCBs congeners indicated that there may be other input sources of PCBs into the inner shelf of the ECS.

The Changjiang-derived sediments is mainly deposited in the Changjiang Estuary north of $30^{\circ} \mathrm{N}$, accounting for about $40 \%$ of the total amount, while $32 \%$ is deposited in the Min-Zhe coastal mud area (Lin et al. 2013). In the south of $28^{\circ} \mathrm{N}$, it is proposed that there is a natural sedimentation process for OM and PCBs (Duan et al. 2013). Another research on sedimental PCBs in the inner shelf of the ECS studied partly by OM indicators has also revealed the difference on PCBs deposition, with Changjiang input as the main origin in the north of $29^{\circ} \mathrm{N}$ while both local coastal sources and Changjiang input are the main PCBs origins in the south (Fan et al. 2014). These studies suggest that there may be a boundary for the deposition of organic pollutants in the inner shelf.

Combined with sedimentary features of matters transported by Changjiang and the spatial distribution characteristics of PCBs, the sampling sites are classified into two parts along the extension of Hangzhou Bay to investigate the existence of the boundary (Fig. 2). The two parts are the combinations of transects of A1-A7 (37 sites) and that of A8-A13 (35 sites) (Fig. 1) respectively and the boundary locates about at $30^{\circ} \mathrm{N}$. In the north of $30^{\circ} \mathrm{N}$, the spatial distributions of PCBs were in high accordance with clay\%, TOC\% and TN\% (Fig. 3) and there were significant correlations between these factors and all PCBs congener groups ( $p<0.01$ ) (Fig. 5, Table S4, Supplementary Data). The results agreed well with previous reports of the deposition of riverine input PCBs in the Changjiang Estuary and its adjacent regions (Lin et al. 2013) which are closely related to the intensified flocculation and gravitational sedimentation of suspended particulate matter (SPM) indicated by clay and terrestrial organic matters (Fan et al. 2014). In the south of $30^{\circ} \mathrm{N}$, the spatial distributions of $\Sigma_{39} \mathrm{PCBs}, \Sigma_{3-5 \mathrm{Cl}} \mathrm{PCBs}$ and $\Sigma_{7 \mathrm{I}} \mathrm{PCBs}$ are dramatically different from that of clay\%, TOC\% and TN\%, while $\Sigma_{1-2 \mathrm{Cl}} \mathrm{PCBs}$ and $\Sigma_{6-10 \mathrm{Cl}} \mathrm{PCBs}$ are largely similar to the latter (Fig. 5). Correlation analysis also presented stronger correlations of $\Sigma_{1-2 \mathrm{Cl}} \mathrm{PCBs}$ and $\Sigma_{6-10 \mathrm{Cl}} \mathrm{PCBs}$ with clay\%, TOC $\%$ and TN $\%$ than $\Sigma_{39} \mathrm{PCBs}$, $\Sigma_{3-5 C l} \mathrm{PCBs}$ and $\Sigma_{7 \mathrm{I}} \mathrm{PCBs}$ (Fig. 5). As for $\Sigma_{1-2 \mathrm{Cl}} \mathrm{PCBs}$, their stronger migration ability (Hong et al. 2003; Zhou et al. 2012) and coastal discharge source may lead to their spread and similar distribution to clay $\%$, TOC $\%$ and TN $\%$ in the south of $30^{\circ} \mathrm{N}$. For $\Sigma_{6-10 \mathrm{Cl}} \mathrm{PCBs}$ (Fig. 5), the good agreement with these sediment factors in the south of $30^{\circ} \mathrm{N}$ can be attributed to their weaker migration ability and lower contents as well as lower detection frequencies (Yang et al. 2011). The dramatical difference on the relationships between sediment properties and $\Sigma_{39} \mathrm{PCBs}$, $\Sigma_{3-5 C l} \mathrm{PCBs}$ being of dominant congener groups and $\Sigma_{7 \mathrm{I}} \mathrm{PCBs}$ being of PCB indicator in the north and south of $30^{\circ} \mathrm{N}$ suggested that there is indeed a clear boundary and the deposition of PCBs on both sides of the
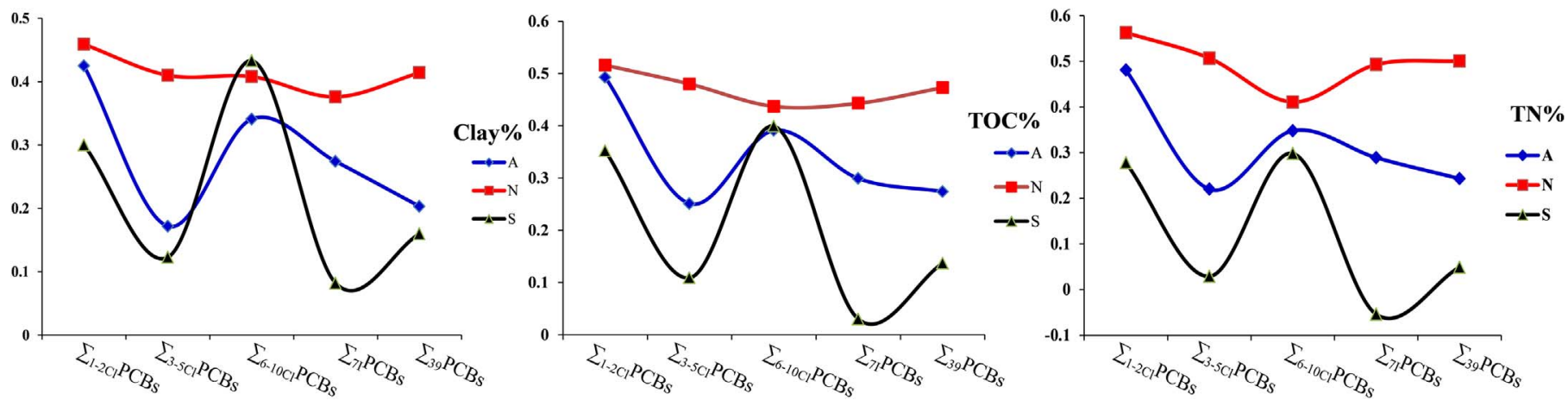

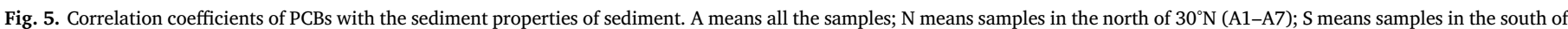
$30^{\circ} \mathrm{N}(\mathrm{A} 8-\mathrm{A} 13)$. 
boundary are controlled by their terrestrial sources and hydrodynamic conditions. In the north of $30^{\circ} \mathrm{N}, \mathrm{PCB}$ distribution is controlled by Changjiang input and deposition of SPM, while in the south of $30^{\circ} \mathrm{N}$ it might be more closely related to the local coastal source (Fan et al. 2014).

Based on high-resolution sampling and high-resolution mass spectrometry analysis, the homolog and congener patterns of PCBs as well as their spatial patterns in the inner shelf adjacent to Changjiang Delta have been critically studied in this paper. The spatial distributions of $\Sigma_{39}$ PCBs covering $1 \mathrm{Cl}$ to $10 \mathrm{Cl}$ PCB and the congener groups based on chlorine numbers all presented a seaward decreasing trend, comparable to previous reports in the ECS. Tetra-CBs were the dominant congeners and low chlorinated PCBs $\left(\Sigma_{3-5 \mathrm{Cl}} \mathrm{PCBs}\right)$ were the predominated compositions. There might be a deposition boundary of $30^{\circ} \mathrm{N}$ for PCBs in ECS and adjacent shelf. In the north of $30^{\circ} \mathrm{N}$, PCBs deposition was controlled by riverine input of Changjiang and hydrodynamic conditions while in the south PCBs were closely related to local coastal source. In all, the combination of high-resolution sampling and highresolution mass spectrometry analysis provide us a novel protocol for identifying the environmental behaviors of POPs more precisely.

\section{Acknowledgement}

This work was supported by the National Natural Science Foundation of China (21407086, 21477138, 41676063 and 41521064), State Key Laboratory of Environmental Chemistry and Ecotoxicology Open Fund (KF2016-12) and the China Postdoctoral Science Foundation (2016M602210). We thank the captain and crews of R/V Runjiang 1, Huihui Pan for sampling assistance. We also thank Limeng Gao, Lu Qiu and Limin Hu for their technical assistance in this study.

Supplementary data to this article can be found online at http://dx. doi.org/10.1016/j.marpolbul.2017.07.036.

\section{References}

Adeleye, A.O., Jin, H.Y., Di, Y.N., Li, D.H., Chen, J.F., Ye, Y., 2016. Distribution and ecological risk of organic pollutants in the sediments and seafood of Yangtze Estuary and Hangzhou Bay, East China Sea. Sci. Total Environ. 541, 1540-1548.

An, Q., Wu, Y., Wang, J., Li, Z., 2009. Heavy metals and polychlorinated biphenyls in sediments of the Yangtze river estuary, China. Environmental Earth Sciences 59, 363-370.

Bigus, P., Tobiszewski, M., Namiesnik, J., 2014. Historical records of organic pollutants in sediment cores. Mar. Pollut. Bull. 78, 26-42.

Chang, B.V., Liu, W.G., Yuan, S.Y., 2001. Microbial dechlorination of three PCB congeners in river sediment. Chemosphere 45, 849-856.

Convention, Stockholm, 2015. Stockholm Convention on Persistent Organic Pollutants (POPs). Switzerland, Geneva.

Duan, X., Li, Y., Li, X., Li, M., Zhang, D., 2013. Distributions and sources of polychlorinated biphenyls in the coastal East China Sea sediments. Sci. Total Environ. 463, 894-903.

Dunnivant, F.M., Coates, J.T., Elzerman, A.W., 2005. Labile and non-labile desorption rate constants for $33 \mathrm{PCB}$ congeners from lake sediment suspensions. Chemosphere 61, 332-340.

Fan, Y., Lan, J., Li, H., Cao, Y., Zhao, Z., Wang, J., Zhao, M., Jiang, G., 2014. Use of lipid biomarkers for identification of regional sources and dechlorination characteristics of polychlorinated biphenyls in the East China Sea. Sci. Total Environ. 490, 766-775.

Gao, S., Chen, J., Shen, Z., Liu, H., Chen, Y., 2013. Seasonal and spatial distributions and possible sources of polychlorinated biphenyls in surface sediments of Yangtze Estuary, China. Chemosphere 91, 809-816.

Gao, L., Huang, H., Liu, L., Li, C., Zhou, X., Xia, D., 2015. Polychlorinated dibenzo-p dioxins, dibenzofurans, and dioxin-like polychlorinated biphenyls in sediments from the Yellow and Yangtze Rivers, China. Environ. Sci. Pollut. Res. 22, 19804-19813.

Hong, S.H., Yim, U.H., Shim, W.J., Oh, J.R., Lee, I.S., 2003. Horizontal and vertical distribution of PCBs and chlorinated pesticides in sediments from Masan Bay, Korea. Mar. Pollut. Bull. 46, 244-253.

Hong, Y., Chunhong, Z., Xiaoxiong, Z., 2009. Investigation of pollution characteristics of polychlorinated biphenyls in the typical drinking water sources in Jiangsu Province, China. Environ. Monit. Assess. 158, 573-579.

Jiang, Q., Zhou, H., Xu, D., Chai, Z., Li, Y., 2007. Characteristics of PCB congeners and homologues in Chinese transformer oil. China Environ. Sci. 27, 608-612.

Jonsson, A., Gustafsson, O., Axelman, J., Sundberg, H., 2003. Global accounting of PCBs in the continental shelf sediments. Environmental Science \& Technology 37 245-255.

Lai, Z., Li, X., Li, H., Zhao, L., Zeng, Y., Wang, C., Gao, Y., Liu, Q., 2015. Residual distribution and risk assessment of polychlorinated biphenyls in surface sediments of the Pearl River Delta, South China. Bull. Environ. Contam. Toxicol. 95, 37-44.

Li, J., Chen, C.L., Li, F.D., 2016. Status of POPs accumulation in the Yellow River Delta: from distribution to risk assessment. Mar. Pollut. Bull. 107, 370-378.

Lin, T., Hu, L., Guo, Z., Zhang, G., Yang, Z., 2013. Deposition fluxes and fate of polycyclic aromatic hydrocarbons in the Yangtze River estuarine-inner shelf in the East China Sea. Glob. Biogeochem. Cycles 27, 77-87.

Liu, J.P., Li, A.C., Xu, K.H., Veiozzi, D.M., Yang, Z.S., Milliman, J.D., DeMaster, D., 2006. Sedimentary features of the Yangtze River-derived along-shelf clinoform deposit in the East China Sea. Cont. Shelf Res. 26, 2141-2156.

Liu, K., Chao, S., Lee, H., Gong, G., Teng, Y., 2010. Seasonal variation of primary productivity in the East China Sea: a numerical study based on coupled physical-biogeochemical model. Deep-Sea Res. II Top. Stud. Oceanogr. 57, 1762-1782.

Lü, X., Zhai, S., 2005. Sources and transport of hydrocarbons in sediments from the Changjiang River Estuary, China. Mar. Pollut. Bull. 50, 1738-1744.

Malisch, R., Kotz, A., 2014. Dioxins and PCBs in feed and food - review from European perspective. Sci. Total Environ. 491, 2-10.

Matturro, B., Ubaldi, C., Grenni, P., Caracciolo, A.B., Rossetti, S., 2016. Polychlorinated biphenyl (PCB) anaerobic degradation in marine sediments: microcosm study and role of autochthonous microbial communities. Environ. Sci. Pollut. Res. 23 12613-12623.

Milliman, J.D., Shen, H.T., Yang, Z.S., Meade, R.H., 1985. Transport and deposition of river sediment in the Changjiang Estuary and adjacent continental-shelf. Cont. Shelf Res. 4, 37-45.

Ono, J., Takahashi, D., Guo, X.Y., Takahashi, S., Takeoka, H., 2012. A numerical study on the seasonal variability of polychlorinated biphenyls from the atmosphere in the East China Sea. Chemosphere 89, 389-397.

OSPAR Commission, 2000. OSPAR Commission for the Protection of the Marine Environment of the North-East Atlantic, Quality Status Report 2000. OSPAR Commission, London, pp. 41-63.

Sinkkonen, S., Paasivirta, J., 2000. Degradation half-life times of PCDDs, PCDFs and PCBs for environmental fate modeling. Chemosphere 40, 943-949.

Sun, J.T., Pan, L.L., Tsang, D.C.W., Zhan, Y., Liu, W.X., Wang, X.L., Zhu, L.Z., Li, X.D., 2016. Polychlorinated biphenyls in agricultural soils from the Yangtze River Delta of China: regional contamination characteristics, combined ecological effects and human health risks. Chemosphere 163, 422-428.

Wang, X., Sun, M., Lil, A., 2008. Contrasting chemical and isotopic compositions of organic matter in Changjiang (Yangtze river) estuarine and East China Sea shelf sediments. J. Oceanogr. 64, 311-321.

Wang, J., Yao, P., Bianchi, T.S., Li, D., Zhao, B., Cui, X., Pan, H., Zhang, T., Yu, Z., 2015 The effect of particle density on the sources, distribution, and degradation of sedimentary organic carbon in the Changjiang Estuary and adjacent shelf. Chem. Geol. 402, 52-67.

Wang, X.Y., Xu, H.Z., Zhou, Y.D., Wu, C.W., Kanchanopas-Barnette, P., 2016. Spatial distribution and sources of polychlorinated biphenyls in surface sediments from the Zhoushan Archipelago and Xiangshan Harbor, East China Sea. Mar. Pollut. Bull. 105, $385-392$.

Yang, R., Jiang, G., Zhou, Q., Yuan, C., Shi, J., 2005. Occurrence and distribution of organochlorine pesticides ( $\mathrm{HCH}$ and DDT) in sediments collected from East China Sea. Environ. Int 31, 799-804.

Yang, Z., Shen, Z., Gao, F., Tang, Z., Niu, J., 2009. Occurrence and possible sources of polychlorinated biphenyls in surface sediments from the Wuhan reach of the Yangtze River, China. Chemosphere 74, 1522-1530.

Yang, H.Y., Xue, B., Jin, L.X., Zhou, S.S., Liu, W.P., 2011. Polychlorinated biphenyls in surface sediments of Yueqing Bay, Xiangshan Bay, and Sanmen Bay in East China Sea. Chemosphere 83, 137-143.

Yang, H.Y., Zhuo, S.S., Xue, B., Zhang, C.L., Liu, W.P., 2012. Distribution, historical trends and inventories of polychlorinated biphenyls in sediments from Yangtze River Estuary and adjacent East China Sea. Environ. Pollut. 169, 20-26.

Yao, P., Zhao, B., Bianchi, T.S., Guo, Z., Zhao, M., Li, D., Pan, H., Wang, J., Zhang, T., Yu, Z., 2014. Remineralization of sedimentary organic carbon in mud deposits of the Changjiang Estuary and adjacent shelf: implications for carbon preservation and authigenic mineral formation. Cont. Shelf Res. 91, 1-11.

Zhang, Z.L., Huang, J., Yu, G., Hong, H.S., 2004. Occurrence of PAHs, PCBs and organochlorine pesticides in the Tonghui River of Beijing, China. Environ. Pollut. 130, 249-261.

Zhang, H., Li, X., Luo, Y., Li, Q., 2011. Depth distribution of polychlorinated biphenyls in soils of the Yangtze River Delta region, China. Geoderma 160, 408-413.

Zhang, T., Yang, W., Chen, S., Shi, D., Zhao, H., Ding, Y., Huang, Y., Li, N., Ren, Y., Mai, B., 2014. Occurrence, sources, and ecological risks of PBDEs, PCBs, OCPs, and PAHs in surface sediments of the Yangtze River Delta city cluster, China. Environ. Monit. Assess. 186, 5285-5295.

Zhao, Z., Li, H., Wang, Y., Li, G., Cao, Y., Zeng, L., Lan, J., Wang, T., Jiang, G., 2013. Source and migration of short-chain chlorinated Paraffins in the coastal East China Sea using multiproxies of marine organic geochemistry. Environmental Science \& Technology 47, 5013-5022.

Zhou, S.S., Shao, L.Y., Yang, H.Y., Wang, C., Liu, W.P., 2012. Residues and sources recognition of polychlorinated biphenyls in surface sediments of Jiaojiang Estuary, East China Sea. Mar. Pollut. Bull. 64, 539-545. 